\title{
Frank-Ter Haar Syndrome, Report of a Case with a Novel Mutation from Iran
}

\author{
Z Hadipour ${ }^{1}$, F Hadipour ${ }^{1}$, H van Bokhoven ${ }^{2}$, R Hennekam ${ }^{3}$ and Y Shafeghati ${ }^{4 *}$ \\ ${ }^{1}$ Medical Genetic Department, Atieh Hospital, Tehran, Iran \\ ${ }^{2}$ Department of Human Genetics, Radboud University Medical Center, The Netherlands \\ ${ }^{3}$ Academic Medical Center, University of Amsterdam, The Netherlands \\ ${ }^{4}$ Sarem Cell Research Center, Sarem Hospital, Tehran, Iran
}

*Corresponding author: Yousef Shafeghati, MD, Sarem Cell Research Center, Sarem Hospital, Tehran, Iran

\begin{abstract}
Frank-ter Haar syndrome is a genetic disease that is transmitted by autosomal recessive pattern with characteristic features such as megalocornea or glaucoma, a developmental delay and multiple congenital anomalies. It was first recognized as a separate entity by Frank, et al. [1] and subsequently confirmed by ter Haar, et al. [2]. The main characteristics are brachycephaly, wide fontanels, prominent forehead, hypertelorism, prominent eyes, megalocornea with or without glaucoma, full cheeks, small chin, bowing of the long bones, and flexion deformity of the fingers. Protruding, simple ears, and prominent coccyx bone can be also regarded as important diagnostic signs. Inheritance most likely is autosomal recessive. Several manifestations such as progressive "coarsening" of the face, hirsutism, gallstones, lingual papillomatosis, and cardiac valve anomalies all point to a possible metabolic basis of the disorder. Here we describe an Iranian 6-year-old boy with this syndrome which is confirmed by a homozygous pathogenic mutation in the SH3PXD2B gene.
\end{abstract}

\section{Keywords}

ter Haar syndrome, Frank-ter haar syndrome, Hypertelorism, Mitral valve insufficiency, Kyphoscoliosis, Skeletal dysplasia, Autosomal recessive, Filamin A

\section{Introduction}

Frank, et al. [1] described an 18-month-old Bedouin girl, born to consanguineous parents, with megalocorneae, multiple skeletal anomalies, and developmental delay, and suggested that this combination of anomalies was a hitherto unreported entity. ter Haar, et al.
[2] reported on three Dutch patients from one family with craniofacial and skeletal characteristics resembling Melnick-Needles syndrome (MNS) but with a fatal course and autosomal recessive inheritance. In 1995, another affected boy, with a similar phenotype, was described from the same but extended family as studied $[2,3]$. These authors suggested that this was an entity distinct from MNS and proposed the eponym ter Haar syndrome. As the patient described by Frank, et al. [1] shows a remarkable resemblance to the patients described by ter Haar, et al. [2], it seems very probable that both patients have the same entity. To recognize the first description by Frank, et al. of their patient as a separate entity it was proposed to rename the disorder as Frank-ter Haar syndrome. Other patients have been reported previously as having the same condition [4-6]. Three probable cases were described as having the serpentine fibula syndrome (SFS) [7], another three possible patients were reported in an abstract [8], as was a pair of sibs with similar findings but severe mental retardation [9].

The gene responsible for Frank-ter Haar syndrome is SH3PXD2B gene. This gene encods a protein which is required for podosome formation and is involved in cell adhesion and migration of numerous cell types. Here we describe an Iranian 6-year-old boy with this syndrome which was confirmed by a homozygous pathogenic mutation in the SH3PXD2B gene.

Citation: Hadipour Z, Hadipour F, van Bokhoven H, Hennekam R, Shafeghati Y (2019) Frank-Ter Haar Syndrome, Report of a Case with a Novel Mutation from Iran. Clin Med Rev Case Rep 6:262. doi. org/10.23937/2378-3656/1410262

Accepted: April 08, 2019: Published: April 10, 2019

Copyright: (C) 2019 Hadipour Z, et al. This is an open-access article distributed under the terms of the Creative Commons Attribution License, which permits unrestricted use, distribution, and reproduction in any medium, provided the original author and source are credited. 


\section{Clinical Report}

This patient was a 5 years 8 months old Iranian boy, the firstborn child of a healthy parents and the only child of a complex consanguineous married couple. He was referred because of Multiple Congenital Anomalies and Dysmorphy. He was product of a normal and uneventful pregnancy, and normal vaginal delivery. Proband's BW was $3030 \mathrm{gm}$., H. $48 \mathrm{~cm}$., and HC $32 \mathrm{~cm}$. His measurements at present are $16 \mathrm{~kg} ., 105$, and 52 $\mathrm{cm}$.

The cardinal features were: Prominent and bossing forehead, wide frontal, down slanted palpebral fissure, posterior rotated ears, short nose and anteverted nostril, prominent lip, hypodontia, gum hypertrophy, narrow palate, micrognathia, inverted nipples, ventricular septal defect, kyphoscolisis, joint stiffness brachycamptodactyly in hands, flat feet, and undescended testis.

The diameter of left cornea was $14 \mathrm{~mm}$. and the other $12 \mathrm{~mm}$., and optic swelling (papilledema) with optic atrophy. On a recent cardiac Echo, the findings were: Thick and mixomatous mitral valve, floppy mitral and tricuspid valves, and a history of small VSD that was closed spontaneously.

I have searched the literature and relevant softwares, and found some diagnosis. The diagnoses were: OralFacial-Digital syn., Oculo-Dento-Digital syn., Oto-PalatoDigital syn. and Weaver syndrome. I myself think the last one is better match with the problem. There was a suggestion for CDGs too.

I contacted with Prof. Hennekam in the AMC Amsterdam and sent the complete phenotype of this case. I attached some of photos that may show the phenotype better and I asked him to take a look and let me have his Idea regarding this case? His suggestion after a long time correspondence was Frank-ter Haar syndrome, and referred me to Prof. Hans van Bokhoven in Nijmegen asking him whether he would be prepared to study this patient on a research basis for the known gene. Prof. van Bokhoven told me the entity is heterogeneous. He has a few families in which he has been unable to find a SH3PXD2B mutation. He did whole exome sequencing in them quite some time ago and has had a small number of candidate genes. He suggested that one of the families was from Pakistan and told that he is not sure from which region in Iran your family is coming from and are they relatives? Indeed this family was not relative of Pakistani family.

\section{Result}

I sent the blood sample of the patient to Prof. Hans van Bokhoven in Nijmegen with the diagnosis of Frankter Haar syndrome. He analysed the SH3PXD2B gene and the result was a homozygous pathogenic mutation in the SH3PXD2B gene. It was a nonsense mutation c.115G > T(p.(Glu39*)) and truncation of the responsible protein and our clinical impression has been confirmed.

\section{Discussion}

We present here an Iranian patient with clinical findings of Frank-ter-Haar syndrome. The combination of the craniofacial, cardiovascular, and skeletal anomalies support the unique nature of this syndrome. Comparison of the manifestation of this patient with those in previous reported is provided in the following table. Along with the symptoms regarded in the table there are additional signs such as downslanted palpebral fissure, posterior rotated ears, short nose and anteverted nostril, prominent lip, hypodontia, gum hypertrophy, narrow palate, micrognathia, inverted nipples, joint stiffness, brachycamptodactyly in hands, flat feet, and undescending testis [1-7].

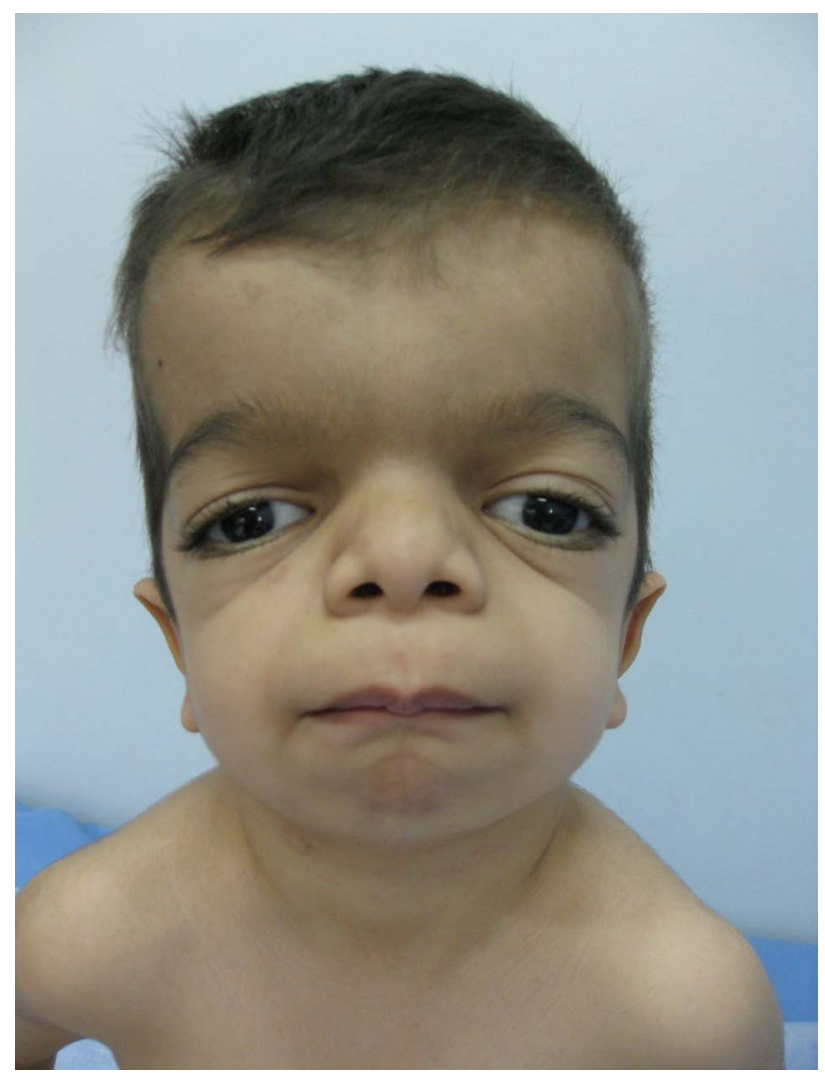

Figure 1: Facial Dysmorfisms: Full cheeks - Micrognathia - Course face; large eyes - Broad nasal tip - Anteverted nostrils; Malocclusion.

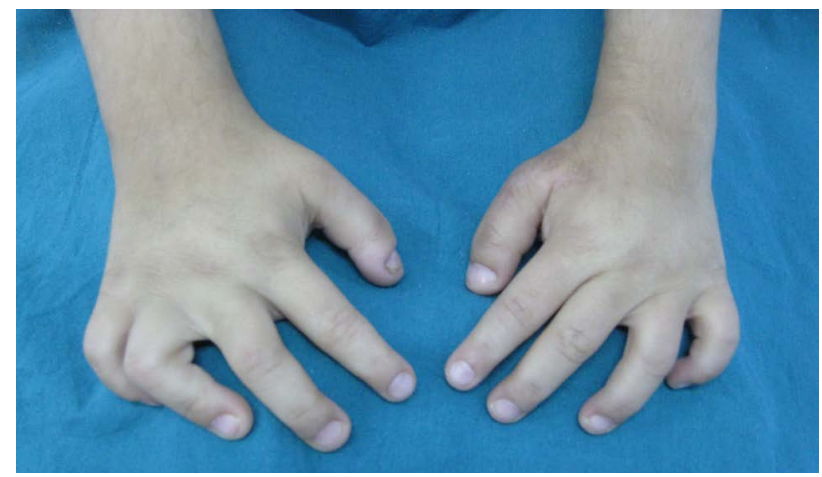

Figure 2: Flexion deformities of fingers - Short phalanges. 
Because of insufficient data the three cases described by Temtamy, et al. [8] were not included. No specific ophthalmological investigation has been performed but the local pediatrician stated the corneae to be unusually large.

Frank-ter Haar syndrome is a rare genetic disorder

Table 1: Frank-ter Haar Syndrome. Comparison of the present patient with those from literature.

\begin{tabular}{|c|c|c|}
\hline Symptoms & ase & $\begin{array}{l}\text { Reported cases in } \\
\text { literature }\end{array}$ \\
\hline Developmental delay & & $9 / 13$ \\
\hline \multicolumn{3}{|l|}{ Craniofacial anomalies } \\
\hline Prominent forehead & + & $16 / 17$ \\
\hline Brachycephaly & + & $12 / 12$ \\
\hline Wide anterior fontanel & + & $15 / 16$ \\
\hline Hypertelorism & + & $18 / 18$ \\
\hline Congenital glaucoma & - & $9 / 13$ \\
\hline Large corneae & + & $13 / 15$ \\
\hline Prominent eyes & + & $18 / 18$ \\
\hline Full cheeks & - & $17 / 17$ \\
\hline Anteverted nostrils & + & $14 / 16$ \\
\hline Broad mouth & + & $14 / 18$ \\
\hline Broad alveolar ridges & & $5 / 7$ \\
\hline Micrognathia & + & $17 / 18$ \\
\hline Protruding ears & + & $11 / 16$ \\
\hline \multicolumn{3}{|l|}{ Skeletal findings } \\
\hline Kyphosis & + & $5 / 11$ \\
\hline Pectus excavatum & & $4 / 16$ \\
\hline Prominent coccyx & & $10 / 11$ \\
\hline Bowing of long bones & + & $13 / 14$ \\
\hline Short hands & + & $11 / 15$ \\
\hline Flexion deformity hands & + & $12 / 16$ \\
\hline Club feet & & $11 / 17$ \\
\hline \multicolumn{3}{|l|}{ Cardiac manifestations } \\
\hline Mitral valve anomaly & & $5 / 9$ \\
\hline Double-outlet right ventricle & & $2 / 17$ \\
\hline Ventricular septal defect & + & $5 / 16$ \\
\hline
\end{tabular}

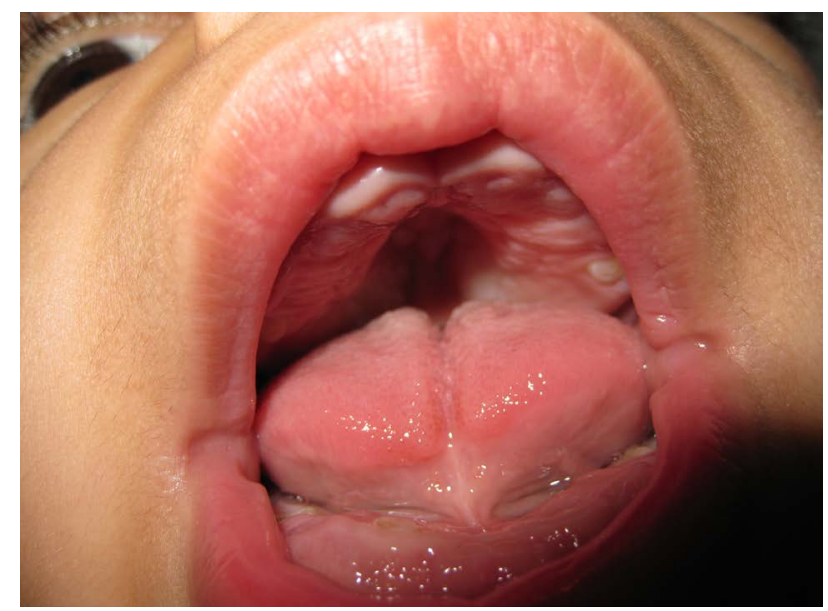

Figure 3: Mouth Deformities; High-arched palate - Gingival hypertrophy - Wide mouth. that results in brachycephaly, a large anterior fontanelle, a prominent forehead, hypertelorism, prominent eyes, megalocornea with or without glaucoma, full cheeks and flexion deformities at the Figure 1 and Figure 2. All of the above mentioned features of the syndrome were also observed in our case. We believe our patient's fontanelle was open with also stenosis of some sutures.

The findings in our case report are similar to the ones described earlier on Frank-ter Haar syndrome (Table 1), broad mouth, broad alveolar ridges, micrognathia, delayed dental development, delayed eruption, impacted

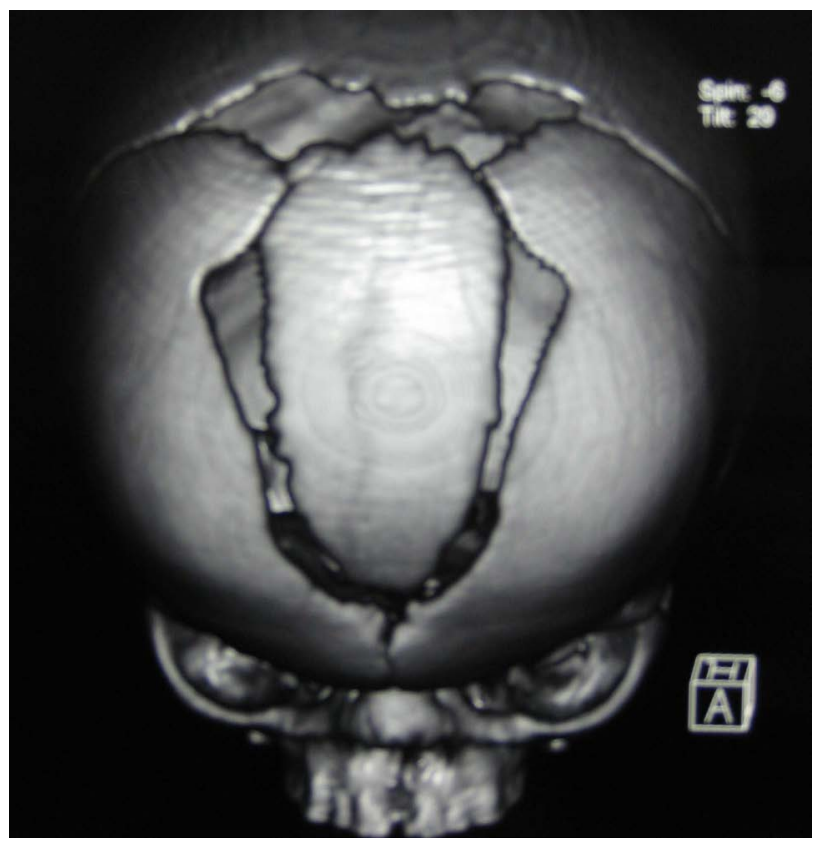

Figure 4: Sagittal craniosynostosis premature fusion of the calvarial sutures, skull MRI.

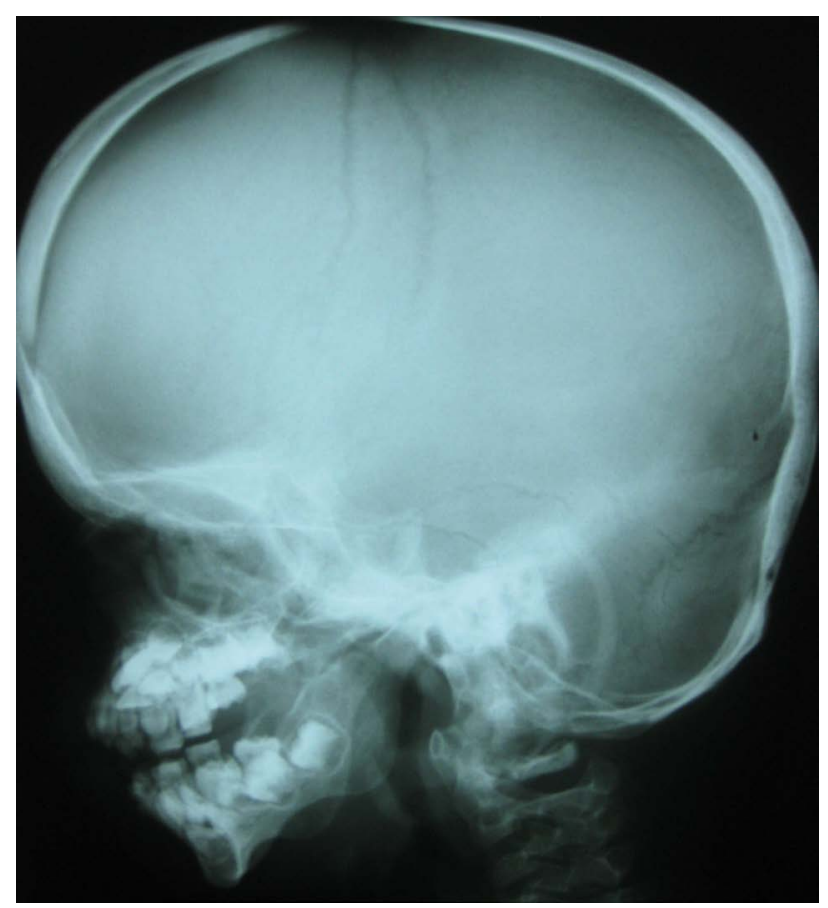

Figure 5: Skull X-Ray: Prominent forehead; small chin; brachycephaly; Wormian bones. 
teeth, anterior open bite, hypoplasia of the teeth, full cheeks, gingival hyperplasia and deep palate (Figure 3).

Sinus underdevelopment or agenesis affects mainly the frontal sinuses; sphenoid sinus involvement is extremely rare [10]. Besides that, it is mentioned in the literature that, sinus agenesis or hypoplasia is seen in syndromes of craniosynostosis, osteodysplasia (Melnick-Needles syndrome) and Down syndrome [11] (Figure 4 and Figure 5). Our patient had agenesis of both the sphenoid and frontal sinuses and underdeveloped ethmoid and maxillary sinuses. There is no information about the paranasal sinuses of patients with Frank-ter Haar syndrome in the literature.

In conclusion, Frank-ter Haar syndrome is a rare autosomal recessive syndrome that involves various multiple maxillofacial anomalies. The report of our case outlines some of the anomalies seen in the patient with Frank-ter Haar syndrome.

\section{Acknowledgement}

Authors like to thank the family for co-operation in this study, and appreciate Prof. R. Hennekam for his kind collaboration in clinical evaluation of the case, and cordially thanks to Prof. $H$. van Bokhoven for his task for molecular analysis of this patient.

\section{References}

1. Frank $Y$, Ziprkowski M, Romano A, Stein R, Katznelson MB, et al. (1973) Megalocornea associated with multiple skeletal anomalies: A new genetic syndrome? J Genet Hum 21: 67-72.

2. ter Haar B, Hamel B, Hendriks J, de Jager J (1982) Melnick-
Needles syndrome: indication for an autosomal recessive form. Am J Med Genet 13: 469-477.

3. Hamel BC, Draaisma JM, Pinckers AJ, Boetes C, Hoppe RL, et al. (1995) Autosomal recessive Melnick-Needles syndrome or ter Haar syndrome? Report of a patient and reappraisal of an earlier report. Am J Med Genet 56: 312-316.

4. Billette de Villemeur T, Bijaoui G, Beauvais $P$, Richardet JM (1992) Bowen syndrome: Congenital glaucoma, flexion contracture of fingers and facial dysmorphism without peroxisomal abnormalities. Europ J Pediat 151: 146-147.

5. Megarbane A, Tomey K, Wakim G (1997) Congenital glaucoma, limb deformities, skeletal dysplasia, and facial anomalies: Report of another family. Am J Med Genet 73: 67-71.

6. Wallerstein R, Scott Cl Jr, Nicholson L (1997) Extended survival in a new case of ter Haar syndrome: Further delineation of the syndrome. Am J Med Genet 70: 267-272.

7. Rosser EM, Mann NP, Hall CM, Winter RM (1996) Serpentine fibula syndrome: Expansion of the phenotype with three affected siblings. Clin Dysmorph 5: 105-113.

8. Temtamy SA, Abdel-Hamid J, Hussein F, Abdel-Salam M, Abdel Meguid N, et al. (1991) Megalocornea and mental retardation syndrome (MMR): Delineation of a new entity (MMR-2). Am J Hum Genet 49: 125.

9. AlKaissi A, Hammou A, Ghachem MB, Nacib MN, Chehida $\mathrm{FB}$, et al. (2003) Siblings with glaucoma, mental retardation and short stature. Clin Dysmorph 12: 191-194.

10. Güven DG, Yilmaz S, Ulus S, Subaşi B (2010) Combined aplasia of sphenoid, frontal, and maxillary sinuses accompanied by ethmoid sinus hypoplasia. J Craniofac Surg 21: 1431-1433.

11. Haktanir A, Acar M, Yucel A, Aycicek A, Degirmenci B, et al. (2005) Combined sphenoid and frontal sinus aplasia accompanied by bilateral maxillary and ethmoid sinus hypoplasia. Br J Radiol 78: 1053-1056. 